\title{
Spirituality and the mental health professions
}

\author{
Monika Pelechova, ${ }^{1}$ Gilly Wiscarson, ${ }^{1}$ Derek K. Tracy ${ }^{1,2}$
}

The Psychiatrist (2012), 36, 249-254, doi: 10.1192/pb.bp.111.036954

${ }^{1}$ Institute of Psychiatry, King's College London; ${ }^{2}$ Oxleas NHS Foundation Trust

Correspondence to Derek K. Tracy (derek.tracy@oxleas.nhs.uk)

First received 19 Sep 2011, final revision 6 Dec 2011, accepted 9 Feb 2012
Aims and method Religion and spirituality are very important personal aspects of many people's lives. Little work has looked at the beliefs of mental health professionals and how they reconcile or benefit from the potential differences of religious faith and evidence-based mental health practice. This study used semistructured interviews to qualitatively explore how professionals from different occupations and faiths conceptualise the relationship between their beliefs and their work.

Results The commonly cited 'conflict' of science and religion was noted, as was the personal support that faith provides for many people. Participants felt their beliefs made them better at their job, not only by reconciling differences from the two paradigms but also by allowing them to recognise compatible attributes of seeking meaning to subjective experience; this had positively influenced their choice of career in mental health. A desire for ongoing opportunity to express and discuss this interface was strongly expressed, but with concern about how this would occur and be perceived.

Clinical implications There is a lack of qualitative research on the religious beliefs of mental health staff. In the UK generally, the role of faith in public life is a strongly debated topic in the context of an increasingly secular and yet multicultural and multifaith society. Our data suggest that professionals' beliefs positively influence their choice of career in mental health and make them feel better equipped to undertake their roles and provide good-quality patient care. There is an expressed need for further opportunities for staff to discuss their beliefs - or lack thereof - and to consider the individual impact of beliefs on their professional life.

Declaration of interest M.P. is a Christian. G.W. is a practising Christian. D.K.T. is a secularist and atheist.
Ill health has always been connected with and considered through spiritual and religious conceptual frameworks, from the philosophical contemplation of distress and the meaning of symptoms to the provision of care. PostReformation Western societies have been marked by a divergence and delineation of the respective roles of faith and science, two distinct paradigms to explain the world and assign meaning. The specific interface of psychiatry/ mental health and religion/spirituality is complex and unique, for many reasons. There is overlap of domains, such as the concepts of consciousness and self, and the explanation of personal worth and distress. Effective practice involves the art of meaningful communication, compassion and empathy. Their support touches the most profound aspects of life and personal meaning, such as relationships, family and wider social functioning.

For many people, religious faith is of enormous - to some people, primary - value, and there is evidence for its supportive and therapeutic role for people with mental illness. ${ }^{1-3}$ Little attention has been given to the religious beliefs of mental health staff. Research, more of which has been carried out in the USA than in the UK, has typically looked at religious affiliations of mental health professionals, which is often lower than that seen in the general population. ${ }^{4-15}$ Scientists typically hold fewer religious beliefs than people with higher education in other fields. ${ }^{16}$ In mental health, early psychoanalysis conceptualised religion with neuroticism, ${ }^{17}$ and religious beliefs are often - correctly - explored as signs of emerging psychopathological grandiosity and delusions. Conversely, religions - a term of enormous breadth and diversity - have often argued about the limits of scientific truth and understanding. With this almost inbuilt antagonism, it is hardly surprising that professionals with an affiliation to both might experience conflict. ${ }^{18}$

The aim of this study was to examine the interplay of religious belief and clinical practice in mental health professionals who hold such beliefs; to explore the validity of the much discussed, sometimes fiercely argued, but in mental health understudied science/faith debate; and to seek out a more nuanced understanding of these issues beyond a conflict paradigm. 


\section{Method}

The study encouraged a value-free approach exploring people's feelings, thoughts, values, beliefs, attitudes and experiences that lend themselves to being captured by qualitative methodology. The strength of qualitative methodology resides in its ability to capture implicit knowledge, individual understanding and interpretation, and to look at phenomena from a deeper perspective. ${ }^{19,20}$

\section{Participants}

The study recruited individuals who work or study in the discipline of mental health at King's College London, and who hold religious or spiritual beliefs, using the King's College circular email. No payment was offered to the participants. Ten people were interviewed: four research workers, three psychiatrists (two of them trainees), one lecturer and two students (one of whom was also a National Health Service clinical support worker).

\section{Materials}

A semi-structured recorded interview schedule was used to explore the participants' views on perceived similarities/ differences and advantages/disadvantages of religion or spirituality to the mental health profession. To illustrate the experience of potential conflict, an enquiry about the specific time of experienced conflict was included, following research conflict paradigms. , $13,16,18,21-26$ Participants' opinions on whether and how the issue should be addressed in education and training were sought. Participants were given the opportunity to express any thoughts they considered important on the topic.

\section{Procedure}

Ethical approval was obtained from King's College London Research Ethics Committee. Circular emails were sent to all students and staff at King's College London. A total of 70 people expressed an interest in the study. Those who were willing to take part and fulfilled eligibility criteria were informed that they would be subjected to a systematic randomisation. $^{27,28}$ The aim was to recruit about 15 participants. Approximately 50 people responded to the second email, so we selected every third person, in the order they replied to the second email. Finally, ten people were able to intend for interview.

The questions covered in the interview were of a personal and a philosophical nature and required consideration of the issues in advance. The interview schedule was emailed to the participants so they could familiarise themselves with the topics to be covered.

All interviews were conducted individually by a single researcher (M.P.), who transcribed the interviews verbatim $^{29}$ and processed them through thematic analysis. ${ }^{30}$

\section{Results}

The aim of this study was to explore how mental health professionals who hold religious and spiritual beliefs conceptualise the relationship between their faith and their profession. A variety of male and female mental health workers from different professions and of differing ages participated in the study. The majority of the participants belonged to a defined faith tradition, while some defined their beliefs as spiritual without specific affiliation.

\section{Participants' characteristics}

Detailed characteristics of the participants are shown in Table 1 .

\section{Themes}

Thematic analysis resulted in nine core themes (Table 2).

\section{Discussion}

There is a lack of exploratory research investigating the opinions of professionals around their own spirituality and how it might impact on patient care. ${ }^{14,18,31-35}$ Research might be hindered by the sheer controversy the topic inevitably draws, by a lack of training in the area, ${ }^{21}$ and by a fear of incompetence to tackle a personal and potentially sensitive area ${ }^{36-38}$ in a multicultural, multi-faith and, in the UK, increasingly secular society. ${ }^{39-41}$

The Psychiatric Bulletin (2008) and the Journal of Mental Health, Religion and Culture (2011) have presented debates on the role of religion and spirituality, both of

\begin{tabular}{|c|c|c|c|c|c|}
\hline & Gender & Age, years & Occupation & Course if student & Beliefs \\
\hline P1 & $\mathrm{F}$ & 35 & Epidemiology researcher & & Yoga \\
\hline $\mathrm{P} 2$ & $\mathrm{~F}$ & 28 & Research worker & & Christian \\
\hline P3 & $\mathrm{F}$ & 23 & Research worker & & Christian \\
\hline P4 & M & 33 & Child psychiatrist & & Muslim \\
\hline P5 & M & 31 & Psychiatrist & MSc child/adult psychiatry & Muslim \\
\hline P6 & $\mathrm{F}$ & 27 & Psychiatrist & MSc philosophy of mental disorder & Christian \\
\hline P7 & M & 22 & & Diploma in mental health nursing & Christian \\
\hline P8 & M & 46 & Lecturer in mental health & & Spiritual \\
\hline P9 & $\mathrm{F}$ & 43 & Research assistant & & Spiritual (nature) \\
\hline P10 & $\mathrm{F}$ & 27 & NHS clinical support worker & MSc philosophy of mental disorder & Spiritual \\
\hline
\end{tabular}

F, female; M, male; NHS, National Health Service. 
Table 2 The major themes arising and examples of their subdescriptors

\begin{tabular}{|c|c|}
\hline Theme & Descriptors \\
\hline $\begin{array}{l}\text { Religion and science working } \\
\text { together }\end{array}$ & $\begin{array}{l}\text { The fields do not conflict but are complementary towards a greater understanding; there are } \\
\text { limits to scientific knowledge; neither is superior; different means to achieve the same goal; } \\
\text { therapeutic similarities of prayer/meditation to cognitive-behavioural therapy and psychotherapy }\end{array}$ \\
\hline Similarities/differences & $\begin{array}{l}\text { Scientific objectivity versus religious subjectivity; one participant disputed this model and viewed } \\
\text { religion as historical and archaeological fact; one participant saw the practice of yoga-based } \\
\text { meditation as being as objective as psychotherapy }\end{array}$ \\
\hline $\begin{array}{l}\text { Advantages/disadvantages of } \\
\text { faith to practice }\end{array}$ & $\begin{array}{l}\text { Faith improves empathy and provides personal coping strategies; some participants felt belief } \\
\text { made them better clinicians; 'extremes' of faith or scientific objectivity could cause harm; needing } \\
\text { to disengage from one to engage with the other; lack of knowledge from faith; beliefs could be } \\
\text { too individualistic; misunderstandings risked disciplinary action }\end{array}$ \\
\hline Need for education & $\begin{array}{l}\text { Excitement there is research on such issues and interfaces; need to contribute to an important } \\
\text { personal issue; desire for greater education on faith; need for a forum to discuss integration of } \\
\text { personal and professional; doubt about realisation of this }\end{array}$ \\
\hline $\begin{array}{l}\text { Feelings about discussing faith } \\
\text { with colleagues }\end{array}$ & $\begin{array}{l}\text { Some variation depending on whether or not colleagues shared religious beliefs; some participants } \\
\text { particularly enjoyed talking with people of other or no faith; three participants would not discuss } \\
\text { faith at all, although two of these might discuss it outside the professional setting }\end{array}$ \\
\hline Impact of faith on career & Religion and spirituality influenced choice of profession; faith affected approach within the profession \\
\hline Perceived internal conflict & $\begin{array}{l}\text { Generally did not feel there was significant internal conflict day by day; deep contemplation of } \\
\text { personal experiences could reveal conflict }\end{array}$ \\
\hline
\end{tabular}

patients and staff, in mental health. Hollins stated a need for more initiatives in this area and proposed that clinicians should explore their own beliefs to be of help to their patients. ${ }^{40}$ Cook contended that religion and spirituality should be recognised as crucial and that further discussion, research and guidelines are required. ${ }^{13}$

Arguments about professionals' beliefs drew strong criticism: some professionals stated religious belief had no place in the discipline of psychiatry and that it risked violating professional boundaries; and some professionals had had negative personal experiences when religious and spiritual issues were applied in the therapeutic setting. It was countered that religion is already addressed in psychiatry in so far as social factors are taken into account: the problem is not asking about issues of meaning to a patient; rather, it is that empathy and understanding are core competencies within psychiatry and that matters on which clinicians may have opposing personal views must be put aside. ${ }^{24,41}$ Concern has been expressed that the Spirituality and Psychiatry Special Interest Group of the Royal College of Psychiatrists could impose its views, influencing policy and resulting in violation of professional boundaries and intolerance of the views of non-believers. ${ }^{24}$

Wagenfeld-Heintz interviewed 30 psychiatrists and psychologists in Michigan, USA, all of whom defined themselves as believers in the Judeo-Christian tradition. ${ }^{18}$ Although, the majority of participants saw religion and spirituality as complementary to their clinical approach, they felt there are boundaries to the extent of this in practice, with constraints by formal regulation and by personal perception of professional boundaries. Psychiatrists and psychologists discussed religious and spiritual matters if that was what the client wanted to do, and stated an awareness of the danger of imposing their beliefs on their clients. Most of the participants said they discussed the issues if the client brought them up, and some of them found it unacceptable if discussion initiated by the patient was neglected.
A study by Dura-Vila and colleagues looked at the attitudes of migrant and UK-born psychiatrists. ${ }^{35}$ Psychiatrists who studied outside the UK often have to get used to different practices regarding the involvement of religion and spirituality in the discipline of mental health, compared with their countries of origin, where it may be considered a natural part of their work. Reasons for religion and spirituality not being a part of routine practice included being afraid of the disapproval of colleagues and supervisors, 'being perceived as anti-modern, unscientific and unprofessional', and being afraid of disapproval from the 'British medical community and secular society'. They noted, however, the importance of religion to them in personal terms, providing them with coping strategies when dealing with difficulties within the professional setting. They used words such as 'frustration' and 'pity' to express feelings about the exclusion of religion from clinical practice.

Although UK-born psychiatrists admitted awareness of the potential positive aspects of religion and spirituality on a patient's health and expressed a wish to see more of it in the profession, their actions revealed the opposite. Lack of training, reliance on the medical model, a clear line between personal beliefs and psychiatric illness, fear of being judged negatively by senior colleagues who show lack of support when they talk about these issues, and formal pressure from the General Medical Council were the main reasons given for the exclusion of religion from clinical practice.

Our work follows previous research in identifying the commonly debated 'conflict' concept. ${ }^{18,25,35}$ Participants saw the dichotomous distinction of two distinct paradigms, one objective and evidence-based and the other lacking this experimental approach, as the greatest dissimilarity between the two, making their integration conflicting. Clinical and institutional mental health practice places an emphasis on scientific, evidence-based explanations, although it focuses on personal values and meanings; this can result in a sense of having 'not to impose', stated 
frequently by all participants and consistent with past work showing that this would be inappropriate behaviour. ${ }^{18}$ The nature of such conflict was not always well defined and differed between participants in our study, with some struggling to reconcile, some avoiding the internal debate, and others eventually finding the two compatible. Most participants who arrived at this latter point had benefited from thinking, reading, guidance and trying to understand the issue. The concept of adopting a philosophical position at either extreme was seen as a major disadvantage, and participants were aware of the importance of maintaining clear boundaries. In parallel, however, participants cited the support offered by their faith to their lives and clinical practice. Participants expressed that their faith conferred a number of benefits on coping with a demanding profession in mental health, providing understanding and support in difficult circumstances

'Psychiatry is very draining, it really affects your personal life, even ... . when you go home, it affects your family life .. religion gives you endurance ... that buffer, that sort of cushion, where you can relax, where you can go and actually recover from that stress.'

We believe this study differs from previous work in assessing values of a broader range of professionals involved in mental health work, both clinical and academic, and in identifying some novel themes. Interestingly, beyond a personal support base, individuals identified drawing useful parallels between the practice of their faith and their work, noting, for example, similarities between prayer and meditation and cognitive-behavioural therapy and psychodynamic psychotherapy. Some participants also believed that being religious or spiritual made them good at their profession. Effective mental health practice requires empathy, understanding and support of others; and although such qualities are not exclusive to people with religious beliefs, participants felt these qualities were fostered and nurtured by faith systems. Similarities of both religious belief and mental health practice in encouraging contemplation, inner contentment and peace, and trying to make sense of a complex, never fully understood world were also noted. Nevertheless, returning to the concept of conflict, the potential for a clinical and inappropriate clash with patients was understood, and most participants stated they expressed their religion or spirituality through their actions and the approach they took to their work rather than discussing their faith directly:

'I have ended up with quite a broad pot of resources to draw from that sort of spans quite a few schools of thought, which is helpful, I think, in connecting with people and ... trying to understand where they're coming from.

Another novel finding we found was that the presence of belief had a positive impact on, and in some cases played a large part in, the choice of career in mental health. Religious and spirituality seem to be deeply embedded in the work of clinicians who have expressed faith, in line with previous work that such values cannot be separated easily from work..$^{18,35,42,43}$ This was shown not only for people who work therapeutically with clients but also for research and education workers:

‘. . one of the best ways you can use your life and one of the exciting ways to sort of become more fulfilled is by reaching out, and helping other people, and thus pursuing that ...'
Contrary to a notion that people might be scared, hesitant or uncomfortable talking about their faith, ${ }^{22,23,36-39}$ participants - albeit a self-selecting group - demonstrated significant enthusiasm about taking part, citing a dearth of opportunities for this, and expressing a desire to discuss the issues more, in a larger, broader forum. There was no agreement, however, as to what that might entail, and there was doubt that didactic teaching was the answer, but there was a general sense of a current lack of occasion to do so and a deficiency of training and support for self-reflection and experiential learning. This supports Culliford's findings that there is a desire for religion and spirituality to be included in the curriculum. ${ }^{44}$ Lack of training on how to deal with these matters is very often cited as a major reason why people working in mental health avoid inclusion of religion and spirituality in their profession..$^{18,35-38,45}$

Developing this further, the majority of individuals did not discuss their beliefs with their colleagues and worried about the potential for conflict. Ecklund \& Park found that opportunities for conflict increase if one's colleagues are negative about the religious or spiritual views of their peers, although the origin of such dispute could come from either side. ${ }^{16}$ The concept of a need for a space for open, honest and reflective thought and discussion, but concern about how this would be perceived, understood or portrayed by others, emerged.

There was general agreement that the two paradigms work together and complement each other. Barbour proposed that a complementary relationship between religion and science is a result of understanding the two to be answers to two different types of question - religion/ spirituality answers 'why?' and science/mental health answers 'how?' - but the domains overlap and neither has exclusivity. ${ }^{25}$

\section{Limitations}

The terms 'religion' and 'spirituality' were purposely used interchangeably in this study to allow and account for a very broad definition of the uniqueness of one's personal beliefs, but this may seem somewhat vague. The fact that interview schedules were sent to the participants in advance may have influenced the process of the interview itself: although this may have yielded more in-depth answers, it could also have resulted in preset responses that were less likely to adapt to the natural flow of the interview. Most previous studies focused on a particular group of mental health professionals, whereas our study involved a broader range of professions, including several participants with limited patient contact outside the research environment. We believed it was preferable in our study to pull in a potentially wider range of opinions and perspectives by interviewing different professionals, although the small number of participants and the nature of qualitative research preclude wider generalisability. For this reason, we did not record the ethnicity or nationality of participants and so cannot delineate our findings in this way.

Perhaps the greatest limitation is that we did not explore the views of people without religious beliefs. Their views on the topic are just as valid and vital as part of a bigger, more inclusive picture of mental health practice. 


\section{Implications}

This study provides additional support to the limited existing data that attention should be paid to the religious/spiritual beliefs of mental health professionals. There is a lack of research, particularly in the UK, and especially of a qualitative nature. ${ }^{18,35}$ This work attempts to stimulate further discussion by stating there is a need for opportunities for mental health professionals to think and talk actively about issues that are important to them in a safe space. It is hoped this paper may provide a platform for others in a similar position to consider their own views and feelings and to seek their own solutions. The article raises ideas and issues that might be addressed in education, training or supervision, drawing a broader picture of a mental health discipline that neglects issues of importance to its professionals and takes a rigid stance towards religion/spirituality.

The study does not aim to resolve the dilemma of inclusion or exclusion of religion or spirituality in a clinical setting, or any potential discrimination that may result, ${ }^{46}$ but it represents the notion of conflict and professionals' need to resolve it. For mental health professionals to perform their work successfully, there is a need to help them become confident in what they do and how they can operate within two different paradigms, both of which are deeply meaningful to them.

In our opinion, this work highlights how people value spirituality not only as a general support in their life but also as a support in their career that makes them better at their job. The conflict exists but does not necessarily overwhelm, and there is evidence that people can not only reconcile but also call on the relevant strengths of each to enhance their practice. Religion can be shown to have instrumental and theological intent for some people, with practitioners adopting a 'methodological agnosticism' in appropriating the skills of each without imposing the world view of either on a patient for whom recovery is the only meaningful outcome. Mental health is unique in its depth of exploration of the psychosocial, and subjectivity and personal meaning are the basis of what we do. Rather than conflict, for many people belief and clinical practice are complementary: they choose to work, study and research in mental health because of what they believe, not in spite of it.

\section{About the authors}

Monika Pelechova is an MSc graduate in mental health studies at the Institute of Psychiatry, King's College London. Gilly Wiscarson is the programme lead for the MSc in Organisational Psychiatry and Psychology at the Institute of Psychiatry, King's College London. Derek K. Tracy is a consultant psychiatrist at Oxleas NHS Foundation Trust and a researcher at the Cognition, Schizophrenia and Imaging Laboratory, Institute of Psychiatry, King's College London.

\section{References}

1 Koenig HG, Mccullough ME, Larson DB. Handbook of Religion and Health. Oxford University Press, 2001.

2 Koenig HG. Faith and Mental Health. Templeton Foundation Press, 2005.

3 Koenig HG. Religion and mental health: what should psychiatrists do? Psychiatr Bull 2008; 32: 201-3.
4 Baetz M, Griffin R, Bowen R, Marcoux G. Spirituality and psychiatry in Canada: psychiatric practice compared with patient expectations. Can J Psychiatry 2004; 49: 265-71.

5 Bergin $A E$, Jensen JP. Religiosity of psychotherapists: a national survey. Psychotherapy 1990; 27: 3-7.

6 Curlin FA, Lawrence RE, Odell S, Chin MH, Lantos JD, Koenig HG, et al. Religion, spirituality, and medicine: psychiatrists' and other physicians' differing observations, interpretations, and clinical approaches. Am J Psychiatry 2007; 164: 1825-31.

7 Huguelet P, Mohr S, Borras L, Gillieron C, Brandt P-Y. Spirituality and religious practices among outpatients with schizophrenia and their clinicians. Psychiatr Serv 2006; 57: 366-72.

8 Lawrence RM, Head J, Christodoulou G, Andonovska B, Karamat S, Duggal A, et al. Clinicians' attitudes to spirituality in old age psychiatry. Int Psychogeriatr 2007; 19: 962-73.

9 Neeleman J, King MB. Psychiatrists' religious attitudes in relation to their clinical practice: a survey of 231 psychiatrists. Acta Psychiatr Scand 1993; 88: 420-4.

10 Payman V. Do psychogeriatricians 'neglect' religion? An antipodean survey. Int Psychogeriatr 2000; 12: 135-44.

11 Shafranske EP. Religious involvement and professional practices of psychiatrists and other mental health professionals. Psychiatr Ann 2000; 30: 525-32.

12 Waldfogel S, Wolpe PR, Shmuely Y. Religious training and religiosity in psychiatry residency programs. Acad Psychiatry 1998; 22: 29-35.

13 Cook CCH. The faith of the psychiatrist. Ment Health Relig Cult 2011; 14: 9-17.

14 Simms A, Cook $\mathrm{CCH}$. Spirituality in psychiatry. In Spirituality and Psychiatry (eds CCH Cook, A Powell, A Simms): 1-15. RCPsych Publications, 2009.

15 Swinton J. Researching spirituality and mental health: a perspective from the research. In Spirituality, Values and Mental Health: Jewels for the Journey (eds ME Coyte, P Gilbert, V Nicholls): 292-305. Jessica Kingsley Publishers, 2007.

16 Ecklund $\mathrm{EH}$, Park JZ. Conflict between religion and science among academic scientists? J Sci Study Relig 2009; 48: 276-92.

17 Freud S. Moses and Monotheisism. Hogarth Press and Institute of Psychoanalysis, 1939.

18 Wagenfeld-Heintz E. One mind or two? How psychiatrists and psychologists reconcile faith and science. J Relig Health 2008; 47: 338-53.

19 Lincoln Y, Guba E. Naturalistic Inquiry. SAGE Publications, 1985.

20 Marshall C. Appropriate criteria of trustworthiness and goodness for qualitative research on education organizations. Qual Quant 1985; 19 353-73.

21 Neely D, Minford EJ. Current status of teaching on spirituality in UK medical schools. Med Ed 2008; 43: 176-82.

22 Beckford M, Gammell C. NHS staff face sack if they discuss religion. Daily Telegraph 2009; 5 February (http://www.telegraph.co.uk/news/ religion/4530384/NHS-staff-face-sack-if-they-discuss-religion.html).

23 Jenkins R. Crucifix ban nurse Shirely Chaplin loses NHS discrimination case. The Times 2010; 7 April (http://www.timesonline.co.uk/tol/ comment/faith/article7089691.ece).

24 Poole R, Higgo R. Spirituality and the threat to therapeutic boundaries in psychiatric practice. Ment Health Relig Cult 2011; 14: 19-29.

25 Barbour IG. When Science Meets Religion. HarperOne, 2000.

26 Poole R, Higgo R, Strong G, Kennedy G, Ruben S, Barnes R, et al. Religion, psychiatry and professional boundaries. Psychiatrist 2008; 32: 356-7.

27 Coolican H. Research Methods and Statistics in Psychology, 4th edn Hodder Arnold, 2004.

28 Johnson JB, Reynolds HT, Mycoff J. Political Science Research Methods, 6th edn. CQ Press, 2007.

29 Atkinson JM, Heritage J. Structures of Social Action: Studies in Conversation Analysis. Cambridge University Press, 1984. 
30 Braun V, Clark V. Using thematic analysis in psychology. Qual Res Psychol 2006; 3: 77-101.

31 Culliford L, Eagger S. Assessing spiritual needs. In Spirituality and Psychiatry (eds CCH Cook, A Powell, A Sims): 16-38. RCPsych Publications, 2009

32 Langlands C, Mitchell D, Gordon T. Spiritual competence: mental health and palliative care. In Spirituality, Values and Mental Health: Jewels for the Journey (eds ME Coyte, P Gilbert, V Nicholls): 173-81. Jessica Kingsley Publishers, 2007

33 Royce-Davis J. The influence of spirituality on community participation and belonging: Christina's story. Couns Values 2000; 44: 135-42.

34 Verhagen PJ, van Praag HM, Lopez-lbor Jr JJ, Cox JL, Moussaoui D. Religion and Psychiatry: Beyond Boundaries. John Wiley \& Sons, 2010.

35 Dura-Vila G, Hagger M, Dein S, Leavey G. Ethnicity, religion and clinical practice: a qualitative study of beliefs and attitudes of psychiatrists in the United Kingdom. Ment Health Relig Cult 2011; 14: 53-64.

36 Ellis MR, Vinson DC, Ewigman B. Addressing spiritual concerns of patients: family physicians' attitudes and practices. J Fam Pract 1999; 48: 105-9.

37 MacLean CD, Susi B, Phifer N, Schultz L, Bynum D, Franco M, et al. Patient preference for physician discussion and practice of spirituality. J Gen Intern Med 2003; 18: 38-43.

38 Maugans TA, Wadland WC. Religion and family medicine: a survey of physicians and patients. J Fam Pract 1991; 32: 210-3.
39 Senghera R. Equality and human rights approaches in the NHS: making spirituality in mental health care count? In Spirituality and Mental Health (ed P Gilbert): 315-34. Pavilion Publishing, 2011.

40 Hollins S. Understanding religious beliefs is our business. Invited commentary on ... Religion and mental health. Psychiatr Bull 2008; 32: 204.

41 Poole R, Higgo R. Psychiatric Interviewing and Assessment. Cambridge University Press, 2006.

42 Richards PS, Rector JM, Tjelveit AC. Values, spirituality and psychotherapy. In Integrating Spirituality into Treatment: Resources for Practitioners (ed WR Miller): 133-60. American Psychological Association, 1999.

43 Shafranske EP, Malony HN. Religion and the clinical practice of psychology: a case for inclusion. In Religion and the Clinical Practice of Psychology (ed EP Shafranske): 561-86. American Psychological Association, 1996

44 Culliford L. Teaching spirituality and health care to third-year medical students. Clin Teach 2009; 6: 22-7.

45 Gerson J, Allen R, Gold J, Kose G. Multiple belief systems in psychotherapy: the effects of religion and professional beliefs on clinical judgment. J Contemp Psychother 2000; 30: 27-32.

46 Poole R, Higgo R. Clinical Skills in Psychiatric Treatment. Cambridge University Press, 2008.

\title{
Sector and functional models of consultant care: in-patient satisfaction with psychiatrists
}

\author{
Richard Laugharne, ${ }^{1,2}$ Milind Pant ${ }^{1}$
}

The Psychiatrist (2012), 36, 254-256, doi: 10.1192/pb.bp.111.037333

${ }^{1}$ Cornwall Partnership NHS Foundation

Trust, Liskeard, Cornwall, UK

${ }^{2}$ Peninsula Medical School, Plymouth,

Devon, UK

Correspondence to Richard Laugharne (richard.laugharne@pms.ac.uk)

First received 6 Oct 2011, final revision 9 Jan 2012, accepted 29 Feb 2012
Aims and method To investigate in-patient satisfaction with psychiatrists, comparing National Health Service (NHS) trusts with sector consultants against NHS trusts with separate in-patient and community consultants (the functional model). The Care Quality Commission's in-patient survey was used, comparing mean scores on four questions concerning patient satisfaction with consultants.

Results Patients scored higher for being treated with respect in trusts with sector consultants. In questions concerning trust, being listened to and getting adequate time, patient satisfaction scores were again higher for sector consultants, but did not reach $5 \%$ significance.

Clinical implications Moving to a split between in-patient and community consultants may reduce in-patient satisfaction with care. The continuity of care with sector-based consultants may be a factor in greater in-patient satisfaction.

Declaration of interest R.L. has argued strongly to maintain the sector model at the NHS trust in which he works.
In general adult mental health services in England, there has been a recent shift from a sector model, in which the consultant psychiatrist cares for both in-patients and out-patients from one geographical area, to a model of in-patient consultants and community consultants (the functional model). ${ }^{1,2}$ This has provoked some debate among psychiatrists and mental health leaders. ${ }^{3}$ The sector model has the advantage of continuity of care in that the same consultant cares for the patient in and out of hospital. The functional in-patient/out-patient model has the advantage of avoiding many consultants feeding into an in-patient unit, with potentially better consultant leadership on wards.

Despite the heated debate, there is limited evidence to base judgements on which model might be better for 